Introduction to the Guest Editor

\title{
Jennifer Suzanne Davids, MD, FACS, FASCRS
}

\author{
Scott R. Steele, MD, MBA, FACS, FASCRS ${ }^{1}$ \\ ${ }^{1}$ Department of Colorectal Surgery, Cleveland Clinic, Cleveland, Ohio \\ Clin Colon Rectal Surg 2019;32:403-404.
}

Dr. Jennifer Suzanne Davids is a staff colon and rectal surgeon and an Associate Program Director of the General Surgery Residency at the University of Massachusetts Memorial Medical Center and an assistant professor of surgery at the University of Massachusetts Medical School in Worcester, MA. Jennifer was born in Boston, MA and received her Biochemical Sciences degree at Harvard College, graduating cum laude. She then went on to the Boston University School of Medicine and finished at the Yale University School of Medicine. She went on to perform her General Surgery Residency training at NewYork-Presbyterian Hospital/Weill Cornell Medical Center and Brigham and Women's Hospital and completed her colon and rectal surgery residency training at the University of Massachusetts, where she has stayed on as staff since 2013.

Jennifer has had an extensive history in award-winning research. Her work was honored with the Owen H. Wangensteen Excellence in Research by the American College of Surgeons in 2016 for research on factors impacting career satisfaction in female physicians, as well as prior awards including the Women in Cancer Research Scholar-in-Training by the American Association of Cancer Research for her efforts in studying a mouse model of FAP. Even at this relatively early stage in her career, she has published multiple peer-reviewed manuscripts and book chapters and has lectured around the United States on various topics of color- ectal surgery. Despite this, she maintains a busy clinical schedule along with teaching medical students, residents, and fellows, and surgical simulation. She is also actively involved in several national committees for the American Society of

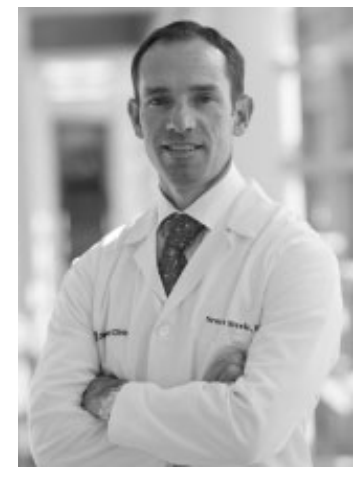

Scott R. Steele, MD, MBA, FACS, FASCRS Colon and Rectal Surgeons, American College of Surgeons, Association of Women Surgeons, Association of Program Directors in Surgery, and Association for Academic Surgery. She serves as a reviewer for several national and international peer-reviewed journals including Annals of Surgical Oncology, World Journal of Surgery, and Diseases of the Colon \& Rectum.

Jennifer is married and has two children. When not working, she enjoys traveling and spending time with family. On a personal note, it has been wonderful to watch her evolve from a colorectal fellow into an emerging thought leader in colorectal surgery in such a short time. No doubt, you will glean her passion for colorectal disease and care for one another throughout this volume. On behalf of the readers and staff of Clinics in Colon and Rectal Surgery, I want to sincerely thank Dr. Davids for serving as a Guest Editor and providing us with an incredible issue on the important topic of surgeon health and avoiding burnout.
Address for correspondence Scott R. Steele, MD, MBA, FACS, FASCRS, Department of Colorectal Surgery, Cleveland Clinic, 9500 Euclid Avenue, Cleveland, $\mathrm{OH} 44195$ (e-mail: harkersteele@me.com).
Issue Theme Surgeon Health; Guest Editor: Jennifer S. Davids, MD, FACS, FASCRS
Copyright (C 2019 by Thieme Medical Publishers, Inc., 333 Seventh Avenue, New York, NY 10001, USA. Tel: +1(212) 584-4662.
DOI https://doi.org/ 10.1055/s-0039-1692707. ISSN 1531-0043. 